\title{
New and emerging treatments for Parkinson disease
}

\author{
The main aim is to maintain quality of life throughout the illness
}

W orld Parkinson's Day commemorates the birth of James Parkinson on 11 April 1755, and it will soon be the 200th anniversary of his description of the "shaking palsy". ${ }^{1}$ In this article I highlight some of the advances in Parkinson disease (PD) therapy since the topic was most recently reviewed in the Journal. ${ }^{2}$

\section{The first step: diagnosis}

The diagnosis of PD is the first step in its management. Even years after PD is diagnosed, patients report that "satisfaction with the explanation of the condition at diagnosis" continues to have an impact on quality of life. ${ }^{3}$ Diagnosis is not always straightforward. In a UK study, only $44 \%$ of patients with PD were initially referred to a neurologist, the other patients being referred to general physicians, orthopaedic surgeons, urologists, psychiatrists and rheumatologists. Pain was the symptom that most frequently impaired the recognition of PD, while frozen shoulder, spondylosis, depression and anxiety were among the common misdiagnoses. ${ }^{4}$ The 1997 charter of the European Parkinson's Disease Association recommends that all patients be referred to a doctor with a special interest in PD. ${ }^{5}$

\section{Managing non-motor symptoms}

Non-motor symptoms, an intrinsic part of PD, have a major impact on quality of life. Anxiety and depression will develop in about $60 \%$ of patients with PD; this is twice the rate seen in the general population. The severity of mood disturbance or apathy is the most important determinant of quality of life in patients receiving treatment, having a greater impact than motor impairment. ${ }^{3,6}$ It is important to determine whether mood fluctuates with the motor "on" and "off" states and might therefore be responsive to dopaminergic therapy, or is more pervasive and requires supplementary pharmacological or non-pharmacological treatment. Even after accounting for the effects of altered mood, "current feelings of optimism" still have an independent influence on quality of life. ${ }^{3}$

Victor SC Fung MBBS, PhD, FRACP.".

1 Westmead Hospital,

Sydney, NSW.

2 University of Sydney,

Sydney, NSW.

vscfung@

ozemail.com.au

doi: 10.5694/mjal5.00155
Impaired olfaction, chronic constipation, and rapid eye movement (REM) sleep behaviour disorder (yelling or thrashing about while dreaming) can predate the onset of motor symptoms by years and even decades. Studies are underway to determine whether these features might be used to enable diagnosis of PD in the premotor stage of the disorder.

\section{Selecting the initial therapy}

Monoamine oxidase B (MAO-B) inhibitors, dopamine agonists (DAs) and levodopa can be employed in the initial treatment of PD, with each approach having its advantages and disadvantages. ${ }^{7}$ As no treatment has been unequivocally shown to either slow or hasten disease progression, the primary goal of therapy should be to restore and maintain quality of life. There is no advantage in delaying therapy if this has a negative effect on quality of life. Initial therapy may influence short- to medium-term outcomes, and should be tailored to the needs of the individual. The MAO-B inhibitor rasagiline may achieve a marginal slowing of disease progression, requires minimal titration and is well tolerated, ${ }^{8}$ but its symptomatic effect may not be as great as that of a DA or levodopa. ${ }^{9}$ It should therefore be considered for patients suffering only minor disability, or for those for whom rapid amelioration of disability is not required.

\section{"General practitioners play a central role in educating patients ... about optimal therapy"}

Early treatment with the DA pramipexole has been shown to reduce the risk of motor complications by $55 \%$ over 2 years, compared with levodopa monotherapy; equivalent to treating $4-5$ patients with pramipexole instead of levodopa to prevent one additional complication. ${ }^{10}$ This benefit, however, needs to be balanced against its potentially serious side effects, especially impulse control disorders which develop in around $17 \%$ of patients using DAs, ${ }^{11}$ and excessive daytime somnolence that can lead to sleep attacks (sudden or irresistible drowsiness that can lead to falling asleep, including while driving).

Levodopa is the most potent and well-tolerated symptomatic treatment, its drawback being an increased risk of dyskinesia. ${ }^{12,13}$ A recent study of more than 1500 patients randomly allocated to initial treatment with an MAO-B inhibitor (selegiline or rasagiline), DA or levodopa showed only very small differences in global outcome at 3-7 years. The best results were achieved with levodopa in terms of mobility and quality of life, and with the levodopasparing agents in terms of avoiding dyskinesias. ${ }^{13}$ The overall results reinforced the view that any of the three options is a reasonable choice as initial therapy.

\section{Advanced therapies for patients with disabling symptoms}

Patients with disabling symptoms who do not respond to adjustments of medication dose should be referred earlier rather than later for consideration of an advanced therapy. 
Only a minority of PD patients who might benefit from an advanced therapy are currently referred for assessment. There is a limit to the relief of severe, unpredictable motor fluctuations that can be achieved by adjusting the dose of standard oral medications, driven in large part by impaired gastric emptying in PD. ${ }^{14}$ To allow patients to make an informed decision about their preferred method of treatment, they should ideally be referred to a specialist with broad experience in advanced therapies.

Two advanced therapies, deep brain stimulation (DBS) and levodopa-carbidopa intestinal gel (LCIG, commonly referred to by its trade name, Duodopa [AbbVie]) have been shown to effectively reduce severe motor fluctuations (including dyskinesias) in randomised controlled studies, decreasing "off" time and increasing quality "on" time by an average of 4 to 5 hours per day. Three trials have found that DBS therapy improved quality of life and motor function better than adjustment of medical therapy. ${ }^{15-17}$ DBS was approved for treating PD in Australia in 2001, but inequality of access remains a problem. Public funding for the stimulator device is limited in many states, so that the therapy is primarily financed by private health insurance or self-funding. More recently, LCIG therapy for severe motor fluctuations has been shown to confer benefits similar to those of subthalamic nucleus DBS. ${ }^{18,19}$ LCIG is delivered as a continuous infusion into the jejunum, bypassing the problem of impaired gastric emptying. Patients need to have a permanent percutaneous endoscopic gastrostomy tube inserted, through which a finer jejunal tube is placed and connected to an external pump that houses the LCIG cassette. LCIG was approved by the Therapeutic Goods Administration in 2008 and has been funded by the Pharmaceutical Benefits Scheme since 2011. There is evidence that LCIG and DBS also improve non-motor symptoms. ${ }^{20,21}$ For patients who need an advanced therapy but prefer a less invasive option than DBS or LCIG, intermittent or continuous subcutaneous delivery of apomorphine (a DA without opioid properties) can be an effective alternative, ${ }^{22,23}$ but its benefits are less well documented.

\section{Conclusion}

There have been significant advances in our understanding of the motor and non-motor symptoms of PD in the past decade. New therapeutic approaches and options are available, and general practitioners play a central role in educating patients about, and facilitating access to, optimal therapy, so that patients can make informed and positive choices.

Competing interests: I have been on advisory boards for Abbott, AbbVie, Allergan, Boehringer-Ingelheim, Hospira, Ipsen, Lundbeck, Novartis, Global Kinetics Corporation, Solvay and UCB, and serve on the editorial boards of Movement Disorders, NPJ Parkinson's Disease, Movement Disorders Clinical Practice, Journal of Clinical Movement Disorders, Fl000Research and Basal Ganglia.

Provenance: Commissioned; externally peer reviewed.

References are available online at www.mja.com.au. 
1 Parkinson J. An essay on the shaking palsy. 1st ed. London: Wittington and Newland, 1817.

2 Hayes MW, Fung VS, Kimber TE, O'Sullivan JD. Current concepts in the management of Parkinson disease. Med J Aust 2010; 192: 144-149.

3 Global Parkinson's Disease Survey Steering Committee. Factors impacting on quality of life in Parkinson's disease: results from an international survey. Mov Disord 2002; 17: 60-67.

4 Williams DR, Lees AJ. How do patients with parkinsonism present? A clinicopathological study. Intern Med J 2009; 39: 7-12.

5 European Parkinson's Disease Association. EPDA charter, 1997. http://www.qegateshead.nhs.uk/parkinsonscharter (accessed Mar 2015).

6 Martinez-Martin P, Rodriguez-Blazquez C, Kurtis MM, et al. The impact of non-motor symptoms on health-related quality of life of patients with Parkinson's disease. Mov Disord 2011; 26: 399-406.

7 Ferreira JJ, Katzenschlager R, Bloem BR, et al. Summary of the recommendations of the EFNS/MDS-ES review on therapeutic management of Parkinson's disease. Eur J Neurol 2013; 20: 5-15.

8 Olanow CW, Rascol O, Hauser R, et al. A double-blind, delayedstart trial of rasagiline in Parkinson's disease. N Engl J Med 2009; 361: 1268-1278.

9 Connolly BS, Lang AE. Pharmacological treatment of Parkinson disease: a review. JAMA 2014; 311: 1670-1683.

10 Parkinson Study Group. Pramipexole vs levodopa as initial treatment for Parkinson disease: a randomized controlled trial. JAMA 2000; 284: 1931-1938.

11 Weintraub D, Koester J, Potenza MN, et al. Impulse control disorders in Parkinson disease: a cross-sectional study of 3090 patients. Arch Neurol 2010; 67: 589-595.

12 Fahn S, Oakes D, Shoulson I, et al. Levodopa and the progression of Parkinson's disease. N Engl J Med 2004; 351: 2498-2508.

13 PD Med Collaborative Group, Gray R, Ives N, et al. Long-term effectiveness of dopamine agonists and monoamine oxidase $B$ inhibitors compared with levodopa as initial treatment for
Parkinson's disease (PD MED): a large, open-label, pragmatic randomised trial. Lancet 2014; 384: 1196-1205.

14 Marrinan S, Emmanuel AV, Burn DJ. Delayed gastric emptying in Parkinson's disease. Mov Disord 2014; 29: 23-32.

15 Deuschl G, Schade-Brittinger C, Krack P, et al. A randomized trial of deep-brain stimulation for Parkinson's disease. NEngl J Med 2006; 355: 896-908.

16 Weaver FM, Follett K, Stern M, et al. Bilateral deep brain stimulation vs best medical therapy for patients with advanced Parkinson disease: a randomized controlled trial. JAMA 2009; 301: 63-73.

17 Williams A, Gill S, Varma T, et al. Deep brain stimulation plus best medical therapy versus best medical therapy alone for advanced Parkinson's disease (PD SURG trial): a randomised, open-label trial. Lancet Neurol 2010; 9: 581-591.

18 Olanow CW, Kieburtz K, Odin P, et al. Continuous intrajejunal infusion of levodopa-carbidopa intestinal gel for patients with advanced Parkinson's disease: a randomised, controlled, double-blind, double-dummy study. Lancet Neurol 2014; 13: 141-149.

19 Fernandez HH, Standaert DG, Hauser RA, et al. Levodopacarbidopa intestinal gel in advanced Parkinson's disease: final 12-month, open-label results. Mov Disord 2014; 24 Dec [Epub ahead of print].

20 Antonini A, Yegin A, Preda C, et al. Global long-term study on motor and non-motor symptoms and safety of levodopacarbidopa intestinal gel in routine care of advanced Parkinson's disease patients; 12-month interim outcomes. Parkinsonism Relat Disord 2015; 21: 231-235.

21 Klingelhoefer L, Samuel M, Chaudhuri KR, Ashkan K. An update of the impact of deep brain stimulation on non motor symptoms in Parkinson's disease. J Parkinsons Dis 2014; 4: 289-300.

22 Martinez-Martin P, Reddy P, Katzenschlager R, et al. Eurolnf: a multicenter comparative observational study of apomorphine and levodopa infusion in Parkinson's disease. Mov Disord 2014; 10 Nov [Epub ahead of print].

23 Frankel JP, Lees AJ, Kempster PA, Stern GM. Subcutaneous apomorphine in the treatment of Parkinson's disease. J Neurol Neurosurg Psychiatry 1990; 53: 96-101. 